UM-HSRI-76-17

\title{
Visibility Distance Through Heat Absorbing Glass
}

Arthur Bernstein

Sponsored by:

PPG Industries, Inc.

June 1976

Highway Safety Research Institute/University of Michigan 
Technical Report Documentation Page

\begin{tabular}{|c|c|c|c|c|}
\hline $\begin{array}{l}\text { T. Ropori No. } \\
\text { UM-HSRI }-76-17\end{array}$ & \multicolumn{2}{|c|}{ 2. Governmont Accession No. } & \multicolumn{2}{|c|}{ 3. Recipientis Cotolog No. } \\
\hline \multicolumn{3}{|c|}{$\begin{array}{l}\text { Virlo and Sublitle } \\
\text { Visibility Distance Through Heat } \\
\text { Absorbing Glass }\end{array}$} & \multicolumn{2}{|l|}{$\begin{array}{l}\text { 5. Roport Dote } \\
\text { June } 1976\end{array}$} \\
\hline \multicolumn{3}{|l|}{$\begin{array}{l}\text { 7. Authors) } \\
\text { Arthur Bernstein }\end{array}$} & \multicolumn{2}{|c|}{$\begin{array}{l}\text { 8. Performing Orgonization Rapori No. } \\
\text { UM-HSRI - 76-17 }\end{array}$} \\
\hline \multicolumn{3}{|c|}{$\begin{array}{l}\text { 9. Portorming Organizotion Name and Address } \\
\text { Highway Safety Research Institute } \\
\text { University of Michigan } \\
\text { Ann Arbor, Michigan } 48109\end{array}$} & 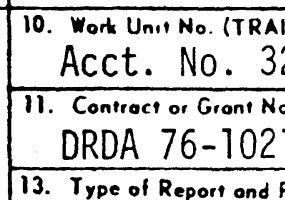 & $\begin{array}{l}0596 \\
-K B 1 \\
\text { ariod Covered }\end{array}$ \\
\hline \multicolumn{3}{|c|}{$\begin{array}{l}\text { 12. Sponsoring Agency Name and Addross } \\
\text { PPG Industries, Inc. } \\
\text { One Gateway Center } \\
\text { Pittsburgh, Pennsylvania } 15222\end{array}$} & 14. Sponsoring Agency C & do \\
\hline \multicolumn{5}{|l|}{ 15. Supplementory Notes } \\
\hline \multicolumn{5}{|c|}{$\begin{array}{l}\text { The distroct } \\
\text { The distances at which pedestrians are first detected by drivers } \\
\text { looking through clear and heat absorbing glass were determined with the } \\
\text { aid of a headlight visibility program. The effects of other vehicle } \\
\text { and environmental factors such as headlamp misaim, headlamp dirt, } \\
\text { pedestrian reflectance, pavement type, low beam glare, high beam glare, } \\
\text { road curvature, change in grade, and wet pavements on detection distance } \\
\text { have also been evaluated. }\end{array}$} \\
\hline $\begin{array}{l}\text { 17. Koy Words } \\
\text { Detection Distanc } \\
\text { Headlamp Misaim, } \\
\text { Glass, Pedestrian } \\
\text { Road Topography }\end{array}$ & $\begin{array}{l}\text { eadlamp Dirt, } \\
\text { Absorbing } \\
\text { lectance, }\end{array}$ & 18. Distribution & ment & \\
\hline 19. Socurity Clossit. (of this rapert) & 20. Socurity Cless & if. (of Atri \& peos) & 21. No. ol Poges & 22. Price \\
\hline
\end{tabular}




\section{ACKNOWLEDGMENT}

The author would like to thank Dr. Paul 01son, the Project Director, for compiling and summarizing the material for the literature review, and for providing information on headlamp misaim and headlamp dirt. 
VISIBILITY DISTANCE THROUGH HEAT ABSORBING GLASS

\section{Introduction}

Much research has been performed on the subject of visibility through heat absorbing glass. For the most part this research has taken the form of nighttime static and dynamic field studies, laboratory visual acuity studies with filters, and analytical studies. To our knowledge, no research has been performed in this area using a headlight visibility computer model. Although the use of a computer model is clearly an analytical approach, its capabilities go beyond paper and pencil analyses. The Headlight Visibility computer Program* (HVP) is capable of determining the effects of many vehicie and environmental factors on visibility distance because it carefully models:

- The human visual detection process.

- The illumination provided by vehicle headlamps.

- Road topography and perspective geometry.

- Pavement reflectivity.

- The disabling effects of glare on target detection.

- Windshield transmissivity.

- Headlamp misaim.

- Headlamp dirt.

With the use of this computer program it is possible to determine the combined effects of windshield transmissivity and other vehicle and environmental factors on driver's visibility distance to pedestrian and delineation targets.

* The complex topography and computer graphics algorithms of this program were developed by the author while he was employed by the Ford Motor Company. The target detection algorithmis have been developed by the author while at HSRI. 


\section{Literature Review}

There have been a substantial number of studies performed in the past to determine the effect of heat absorbing glass on visibility. Those studies which used visibility distance as the measure of visual performance are particularly relevant to our research because we are also using this measure.

The studies measuring visibility distance for heat absorbing glass fall into two basic categories: field tests, and analyses based upon laboratory target detection data. The field studies performed by Roper (1953) and Heath and Finch (1953) are the classic papers often quoted on this subject.

Roper (1953) conducted field tests on an air strip using two identical cars equipped with sealed beam headlamps. Subjects drove vehicles equipped with clear and heat absorbing glass at a speed of $40 \mathrm{mph}$ toward roadside 16 inch square targets of reflectance $7.5 \%$. The distance at which the subjects first detected the targets was recorded.

Detection distances were measured in the absence of glare and in the presence of an oncoming glare vehicle moving at a speed of $40 \mathrm{mph}$. The percent variation in detection distance between clear and heat absorbing glass ranges from 0 to $10 \%$. The average reduction in detection distance, in the absence of glare due to heat absorbing glass was $5.7 \%$. In the presence of an oncoming glare vehicle the average reduction in detection distance for heat absorbing glass was only $2 \%$. The author correctly attributes the improved performance of the heat absorbing glass in the presence of glare to the reduction in glare illumination afforded by the heat absorbing glass. Roper concludes that "unless the driver does practically all of his driving at night, the daytime benefits to be derived from heat absorbing glass windshields offset the small reduction in seeing distance at night." 
Heath and Finch (1953) performed field tests similar to Roper, except that no tests were performed in the presence of a glare vehicle. The detection distance discrepancies between heat absorbing and clear windshields cover approximately the same range as in the Roper study.

A good example of analytical approach to the computation of visibility distance is the paper by Dunipace, Strong and Huizinga (1974). They have used the laboratory target detection data of Blackwell (1952) to compute visibility distance to various roadside targets for low and high beam illumination. The purpose of their study was to analytically determine the effect of heat absorbing glass on visibility distance.

In order to avoid the complexities of pavement reflectance and the precise characterization of background luminance, the authors have used two different types of approximations which they refer to as the ISO-C and ISO-B models. The ISO-C model, which has previously been used by Blackwell (1954) and Haber (1955), assumes that the contrast between the target and the pavement is constant (the underlying assumptions are that the pavement is the background for the target and that pavement reflectivity is constant). Using the ISO-C model, the mechanism for detection is primarily a function of background luminance. As the driver approaches the target, target and background luminance increase simultaneously and at the same rate maintaining contrast constant. As the target gets closer the background gets brighter and the required detection contrast diminishes until the target is visible. The ISO-B model, assumes that the background is of constant luminance, independent of target distance. This is approximately true when the sky is the predominant background for the target. Using the ISO-B model the required detection contrast is constant. As the target gets closer it gets brighter and its contrast increases until the required detection contrast is achieved. The authors have determined that the detection distances 
measured in actual field tests are bracketed by the ISO-B and ISO-C models.

In reality, the pedestrian detection problem is a combination of the ISO-C and ISO-B situations. If the most intense part of the headlamp beam is aimed at the feet, then the pavement forms the background for the pedestrian and the ISO-C model holds. If the most intense part of the headlight beam falls above the waist the sky. forms the background and the ISO-B model holds. Usually, however, the situation is somewhere in the middle and a non homogeneous target detection model such as the one used in the HVP should be used.

Dunipace et al have determined that the ISO-B model more accurately predicts the reduction in visibility distance ranging from 1 to $6 \%$ found by various researchers in actual field tests.

The Computation of Night Visibility Distances

Various researchers have computed night visibility distance from laboratory target detection data. Blackwell (1952) has measured the $50 \%$ probability of detection contrast of homogeneous circular targets against a homogeneous background. Foveal threshold contrasts were determined for subjects with normal acuity between the ages of 20 and 30 years. Threshold contrast was determined parametrically as a function of background luminance, target diameter and exposure time. Figure 1 is representative of the results of these target detection measurements for a .18 second exposure. The threshold detection contrast decreases with increasing background luminance until it reaches a minimum value independent of further increases in.luminance, the Weber contrast. Detection contrast also decreases systematically with increasing target diameter and exposure time.

The Basic Approach to the Computation of Detection Distance The procedure that would be used in computing nighttime detection distance to a small homogeneous target standing against the pavement 


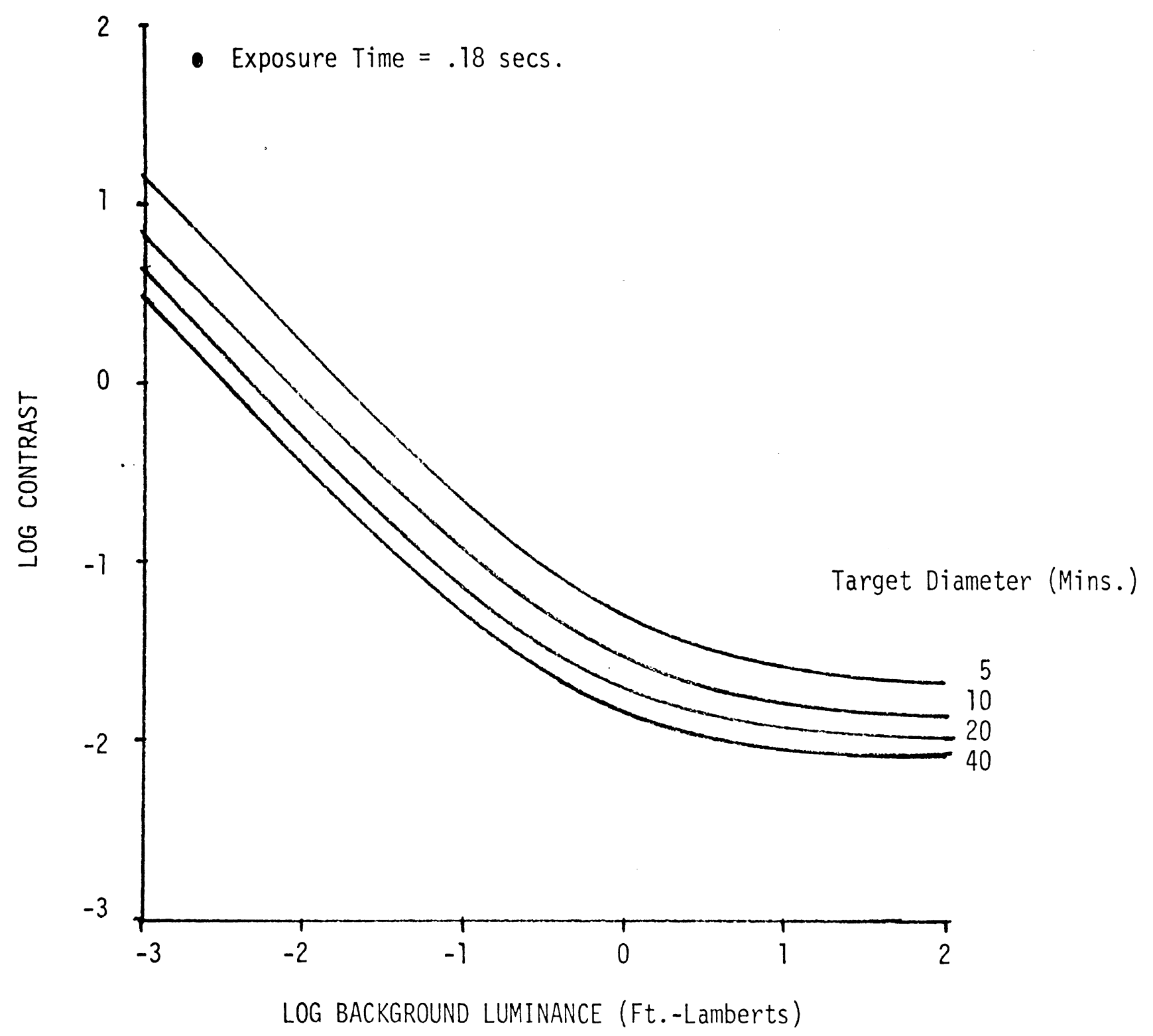

Figure 1. Threshold Contrast as a Function of Background Luminance and Target Diameter; $.18 \mathrm{sec}$. exposure provided best fit to field test data. 
is as follows:

- Compute the luminance of the target by determining the headlamp illumination falling on the target and multiplying it by the target reflectance.

- Compute the luminance of the background by determining the illumination falling on the pavement adjacent to the target (approximately equal to the illumination on the target) and multiplying it by the pavement reflectance.

- Compute the effective circular diameter of the target in minutes of arc from a knowledge of the actual dimensions of the object and its distance from the subject

- Compute the actual contrast of the target, $C=\frac{B_{T}-B_{B}}{B_{B}}$, equal to target luminance minus the background luminance divided by the background luminance.

- Use the appropriate target detection curve (corresponding to the computed target diameter and appropriate exposure time determined by calibration with the field test data) to determine if the actual contrast is greater than the required detection contrast. If the actual contrast is greater, the target is visible at its location, if not it is invisible at its location. By means of repeated trials the precise location at which the target becomes visible may be determined.

The Modelling of Windshield Transmissivity

The fraction of luminous flux that passes through the windshield is characterized by the windshield transmissivity $t$. Thus, if $B_{T}$ and $B_{B}$ are the target and background luminance as measured from the outside of the windshield, the target and background luminance measured from the inside of the windshield is $t B_{T}$ and $t B_{B}$ 
respectively. That is, the windshield acts to reduce the luminance of the target and background by the same identical fraction, keeping contrast constant. At high luminance levels where Weber's law (required contrast is constant) holds the windshield does not reduce visibility. At low luminance levels, the reduction in background luminance produced by the windshield increases the required contrast slightly. This increase in required contrast is responsible in the absence of glare for a small (approximately 6\%) decrease in detection distance when a heat absorbing windshield is used rather than a clear windshield.

In the presence of glare sources the windshield acts to reduce the veiling luminance $B_{V}$ produced by the glare source. The veiling lumiriance at the driver's eye is $t B_{V}$. The reduction in veiling luminance produced by heat absorbing glass partially offsets the reduction in background luminance reducing the decrement in detection distance.

\section{Complicating Factors}

The basic principles in computing detection distance have been outlined above but in actual practice a headlight visibility program must also cope with some additional complicating factors. A few of these will be discussed below.

\section{Complex Topography}

In order to compute the luminance of a target positioned on a curved or hilly road, it is necessary to compute the precise position of the target relative to the headlamp beams. Once this has been determined, the horizontal and vertical angle of the light ray emanating from the headlamp to the target can be computed; from this information and the intensity matrix for each headlamp the candlepower falling on the target may be computed. The mathematical computations involved in computing the Cartesian co-ordinates of the road boundaries and the pedestrian target contour are quite involved. 
To facilitate the verification of these computations a computer graphics capability has been developed to plot the boundaries of the road and the contour of the pedestrian standing on the roadway. Examples of this capability are shown in Figure 2. Figure $2 a$ is a driver's eye perspective drawing of a left horizontal curve, with a rate of curvature of $2 \% / 100 \mathrm{ft}$. and Figure $2 \mathrm{~b}$ is an example of a right horizontal curve. The pedestrian is stationed in the center of the road 400 feet away, in both computer drawings. Figure $2 c$ is a hill crest vertical curve corresponding to a $-8 \%$ change in grade between tangent sections. The rate of change of curvature is $.76 \% / 100 \mathrm{ft}$., the maximum rate permitted at a design speed of $50 \mathrm{mph}$. The pedestrian is located at the right road edge 400 feet away from the car, and is partially obscured by the hill crest. In the HVP, only the non-obscured portion of the pedestrian's contour is used to compute detection distance. Figure $2 \mathrm{~d}$ is an upgrade hill with an $8 \%$ change in grade between tangent sections. The pedestrian is 400 feet away at the right road edge.

\section{Pavement Reflectivity}

Because pavement reflectivity varies as a function of the angle of incidence of the light rays, this angle must also be computed so that the proper pavement reflectance value is used in the computation of pavement luminance. The values of pavement reflectivity used in the program have been measured photometrically on actual concrete and asphalt pavements, Bernstein (1974), Figure 3.

\section{Non-Homogeneous Targets}

Most targets encountered by the driver are not homogeneous in luminance and thus the proper way to make use of the laboratory detection data to predict the visibility of a pedestrian is not obvious. Even the problem of specifying the luminance at various parts of the pedestrian and of his background is quite difficult.

Therefore, in the HVP special algorithms have been developed 


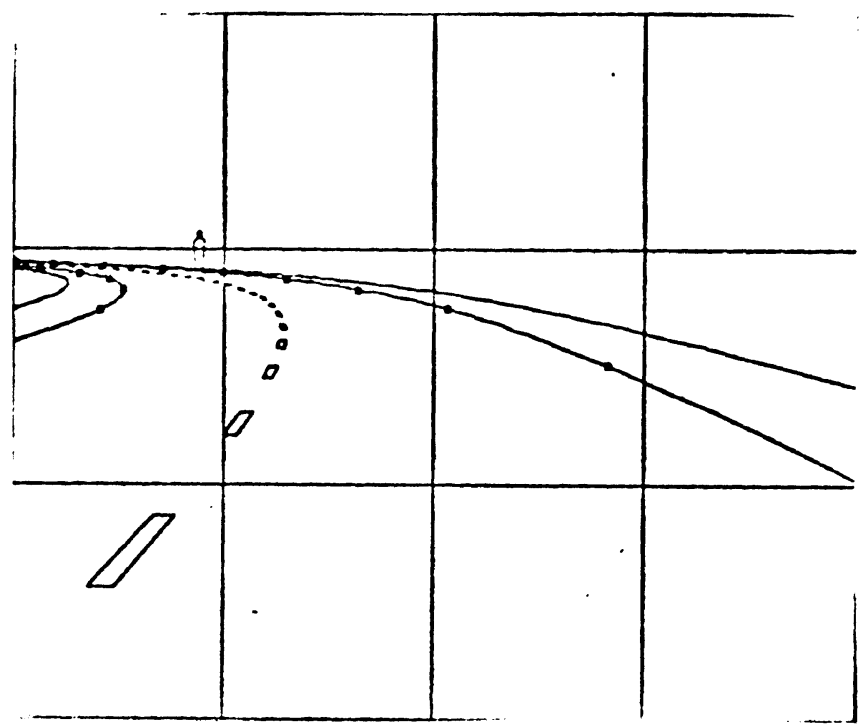

Figure $2 a$.

- $2^{\circ} / 100 \mathrm{ft}$. left curve

- Pedestrian $400 \mathrm{ft}$. away

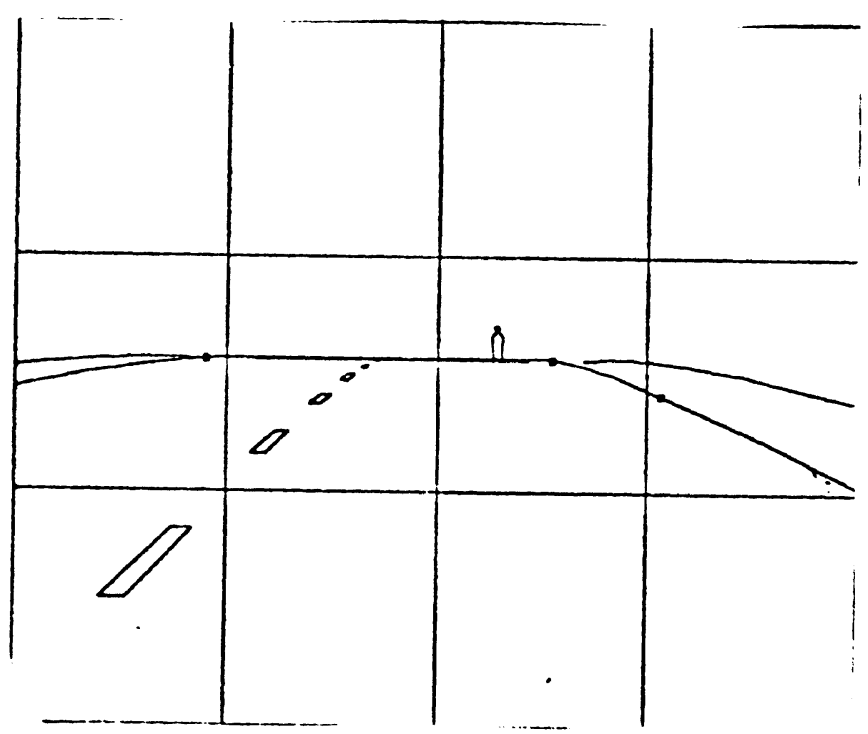

Figure 2c.

- $-8 \%$ Change in grade

- Partially obscured pedestrian at Rt. road edge, $400 \mathrm{ft}$. away

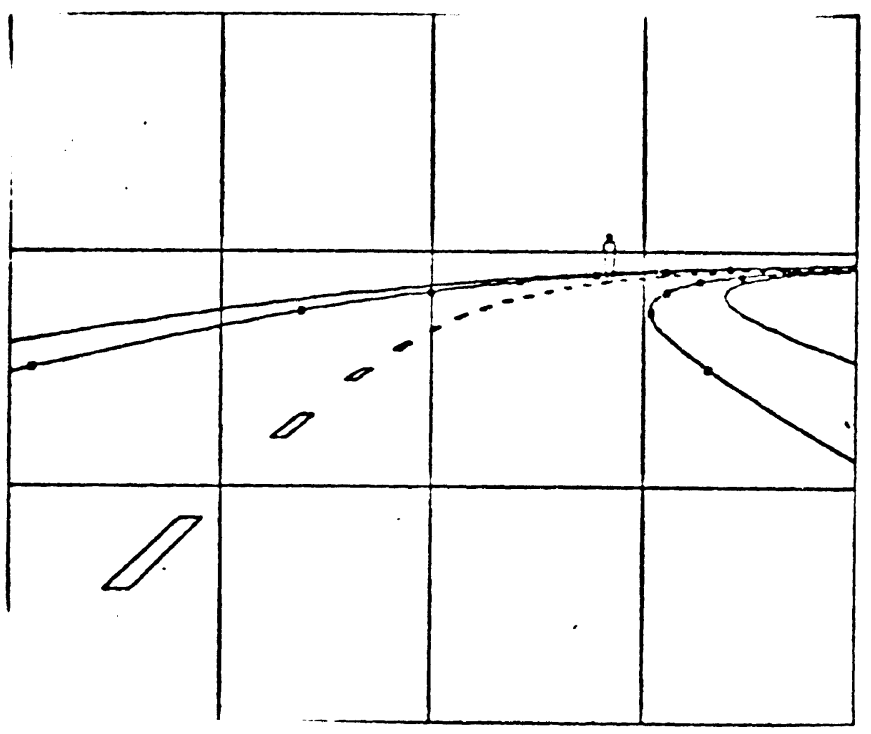

Figure $2 b$.

- $2 \% / 100 \mathrm{ft}$. right curve

- Pedestrian $400 \mathrm{ft}$. away



Figure 2d. .

- $+8 \%$ Change in grade

- Pedestrian at Rt. road edge, $400 \mathrm{ft}$. away

Figure 2. The Complex Topography and Geometric Graphics Capability of the HVP 


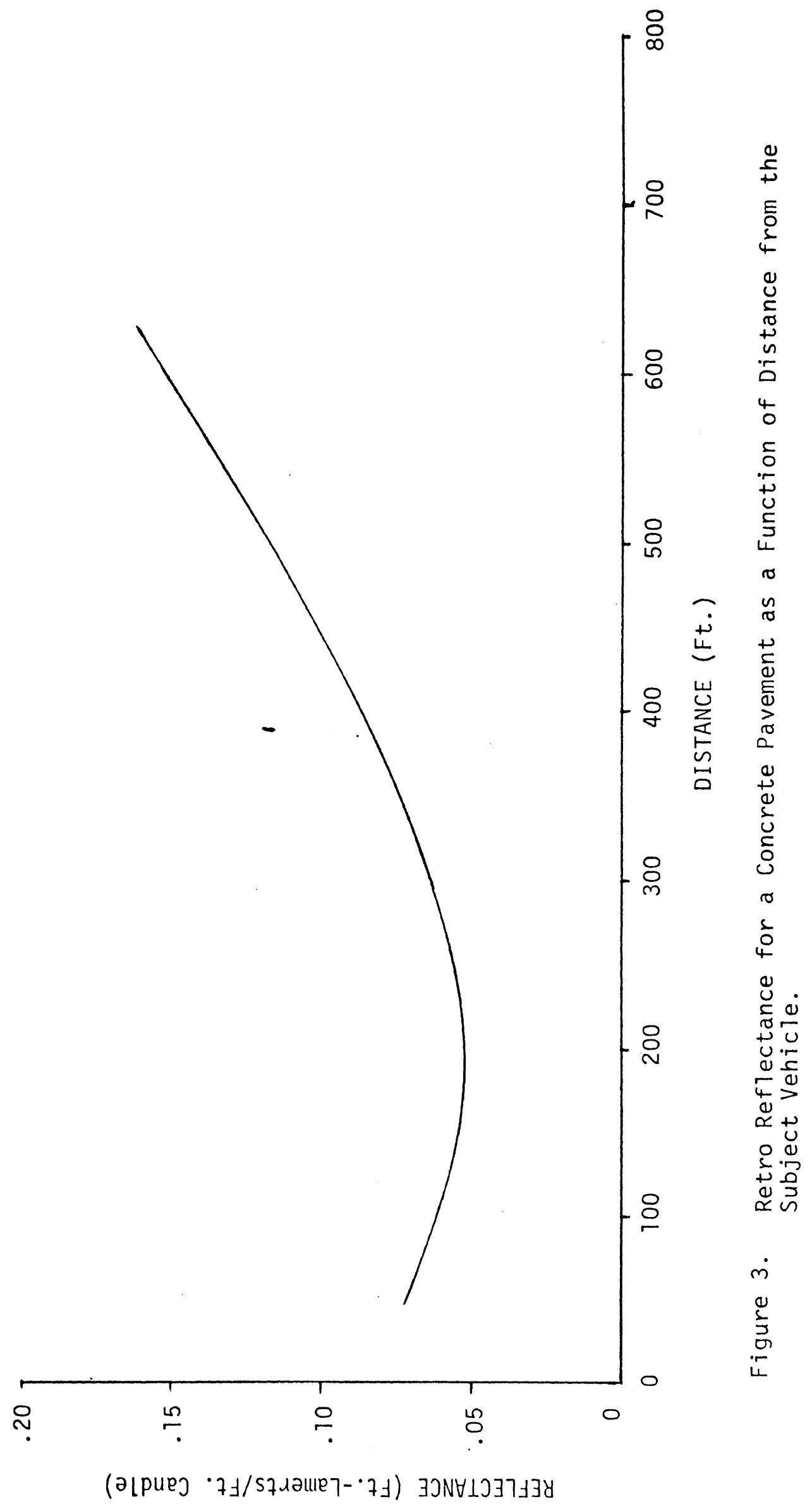


for computing the luminance of the target and its background and for predicting the visibility of non-homogeneous targets. A brief description of these algorithms is presented below.

\section{Background Brightness Evaluation}

A difficult aspect of the pedestrian detection problem is specifying the precise background luminance found adjacent to the pedestrian's contour. (There is good reason to believe that target detection occurs at the contour between target and background. Therefore, a knowledge of the precise luminance distribution along the contour of the pedestrian is necessary for predicting the visibility of the pedestrian.) At present the HVP determines whether each point along the contour of the pedestrian is a pavement or sky point. If the background point is a pavement point the precise distance of this point from the subject vehicle is determined, and the corresponding pavement reflectance and pavement luminance are computed. If the background point is a sky point, its luminance is the ambient Tuminance.

\section{Non-homogeneous Target Detection Model}

A pedestrian target with a non-homogeneous luminance distribution is often only partially visible. That is, detection may first occur when only a fragment of the pedestrian has sufficient contrast to be seen. The HVP uses an algorithm which evaluates the visibility of various portions of the pedestrian's contour as well as the whole contour. The maximum detection distance often occurs when onty a fragment of the pedestrian is visible.

\section{Equations for Specifying Threshold Contrast}

Based upon physiological considerations, Bernstein (1974, 1976) has developed a formalism for predicting the Blackwell threshold contrast data. The latest results of this formulation are a set of equations which specify threshold (50\% probability of detection) 
contrast as a function of background luminance $(.001$ to $100 \mathrm{ft}-\mathrm{L})$, target diameter ( 3 mins to 64 mins) and exposure time (.01 sec to $1.0 \mathrm{sec}$.$) . The correspondence between the values predicted by these$ equations and the raw Blackwell and McCready (1958) data is in many cases within one standard deviation of the experimental data. These equations are used in the HVP to determine if a target has the minimum contrast required for detection.

The basic equations for threshold contrast as a function of Background Luminance, Target Diameter and Exposure Time that are used in the HVP follow below:

$$
C=(E-1)+(E-1) / a B_{B}
$$

where

$C$ is the required threshold contrast

$B_{B}$ is the background luminance in $\mathrm{ft}$-Lamberts

$(E-1)$ is the neural threshold required for detection and is a function of target diameter, TD, and exposure time, $t$.

$$
\left.\begin{array}{l}
E=\exp \{.00567+.052 / T D+.0023 / t+.0037 / t \cdot T D \\
\alpha \text { is a parameter representing the sensitivity of }
\end{array}\right\} \begin{aligned}
& .01 \leq t \leq 1 \mathrm{sec} \\
& 3 \mathrm{~min} \leq T D \leq 64 \mathrm{~min} .
\end{aligned}
$$
the retina and is also a function of $t$ and $T D$.

$$
\begin{array}{ll}
\alpha=.149+.026 \text { lnt }+.161 \mathrm{lnTD}+.02 \mathrm{lnt} \cdot \operatorname{lnTD} & .01 \leq t \leq 1 \mathrm{sec} \\
& 3 \mathrm{~min} \leq \mathrm{TD} \leq 64 \mathrm{~min} .
\end{array}
$$
contrast and is a function of background luminance. The DeGroot, Gebhard (1952) equation for pupil diameter as a function of background luminance was used to develop the expression for $p$.

$$
p=\frac{d^{2}}{7.82} \text { where } d \text { is the diameter of the pupil and is }
$$

given by

$$
\log d=.8558-.000401(\log B+8.07)^{3}
$$

where $B$ is the background luminance in ft-Lamberts.

The curves of log contrast vs. background luminance shown in 
Figure 1, for a .18 second exposure time and target diameters of $5,10,20$, and 40 minutes represent values predicted by the above equations.

Measures of Visual Performance

Both detection distance and recognition distance measures have been widely used to characterize visual performance. Detection distance is the distance at which a target first becomes apparent. The target is amorphous at this distance where its contrast is sufficient for spatial localization but insufficient for shape recognition. Recognition distance is the distance at which the shape and identity of an object may be determined. Recognition distances are shorter than detection distances.

The detection distance measure is used throughout this report because it specifies the maximum distance at which an evasive maneuver may be initiated and because it is more readily computed from laboratory target detection data. Also, most dynamic field tests conducted with pedestrian sithouettes have measured detection distance. The new HSRI headlight-visibility computer program has been validated using the data from such pedestrian detection field tests.

\section{Validation of the Headlight Visibility Program}

The headlight visibility program has been validated by comparing the predictions of the computer model with the field test results of several different researchers. The field test data of Bhise, McMahan, and Farber (1976) were used to validate the program for the visual task of pedestrian detection. In their field tests Bhise et al have measured the maximum distance at which subject drivers could detect $8 \%, 15 \%$ and $25 \%$ reflective silhouettes. These tests were conducted on a straight, flat concrete road with the pedestrian targets located 7 feet to the right of the road center. 
In the field tests, detection distances were determined under both low and high beam illumination where the low beams corresponded to type 2 low beams similar to a GE 4000 low beam while the high beams correspond to type 5 government high beams at 50\% maximum output. These same headlamp beam patterns were used in the headlight visibility program.

The curves of detection distance vs. pedestrian reflectance for low and high beams indicate the predictions of the program whereas the solid dots represent the mean detection distances found in the field tests and the horizontal bars indicate the $\pm 1 \sigma$ variation of the experimental data. As can be seen from Figure 4 the program predicts a 11 the experimental points except one to within one standard deviation. The exception is within $2 \sigma$ of the mean.

\section{Factors Affecting Detection Distance}

The headlight visibility program has been used to examine in detail the relationship between pedestrian detection distance and various other vehicle and environmental variables. The data is always presented in curve pairs which compare the detection distance for a clear windshield to the detection distance for a heat absorbing windshield.

\section{Vertical and Horizontal Misaim}

The effects of vertical and horizontal misaim on detection distance are shown in Figure 5. Both left and right GE 4000 low beams have been misaimed identically. The analys is is for an $8 \%$ reflective pedestrian stationed at the right road edge. Detection distance is very sensitive to changes in vertical misaim but relatively insensitive to changes in horizontal misaim. For a clear windshield, detection distance varies from $105 \mathrm{ft}$. when both headlamps are misaimed down $2^{\circ}$ to $565 \mathrm{ft}$. when both headlamos are misaimed up $2^{\circ}$. The effect of heat absorbing glass is comparatively 


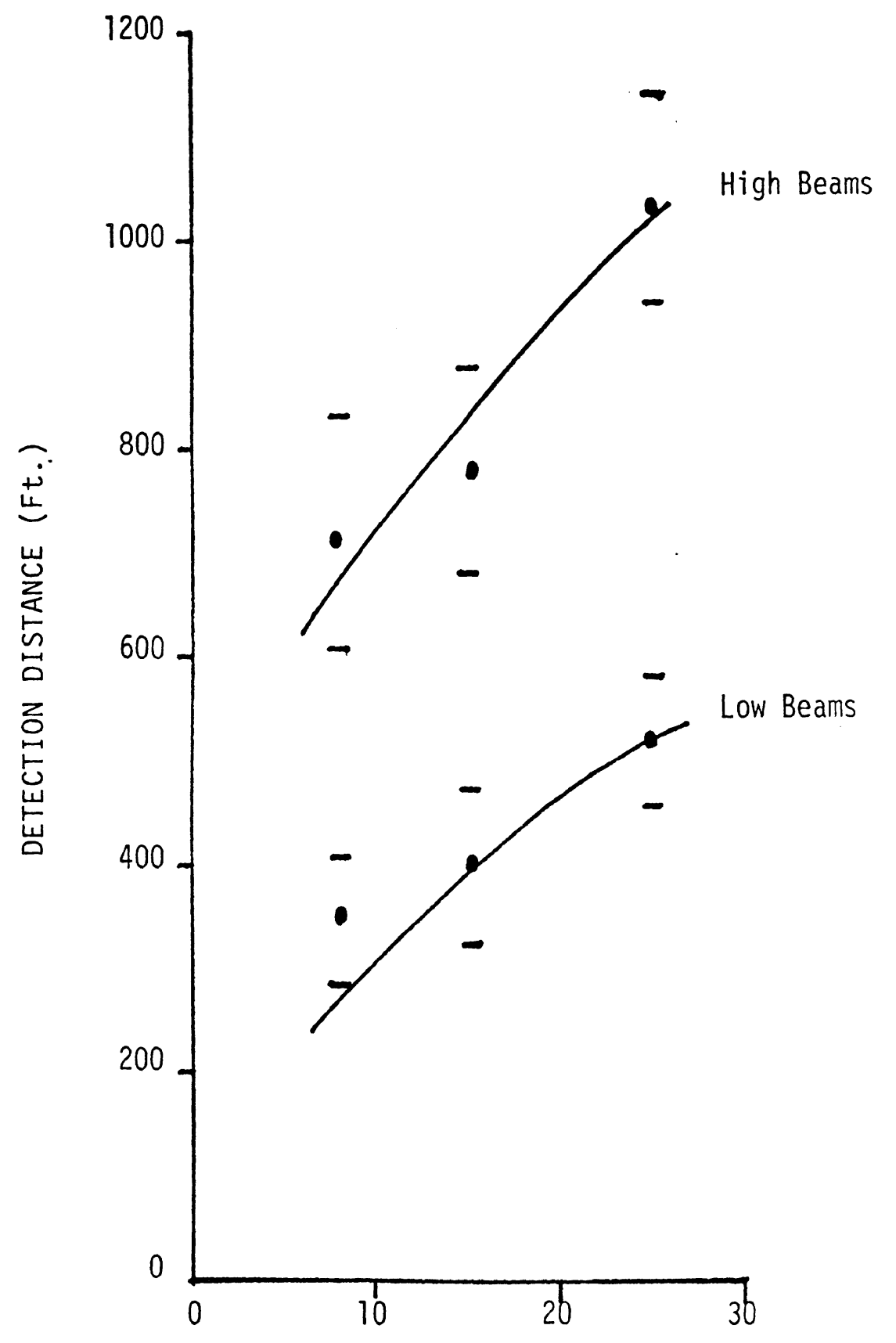

PEDESTRIAN REFLECTANCE, \% (Ft. Lambts/Ft. Candle)

Figure 4. Comparison of predictions of headlight model with field test data; pedestrian $7 \mathrm{ft}$. to the right of road center.

Predictions of model;

- Mean value of field test data (Bhise, McMahan, Farber, 1976)

- 1 o variation limits 


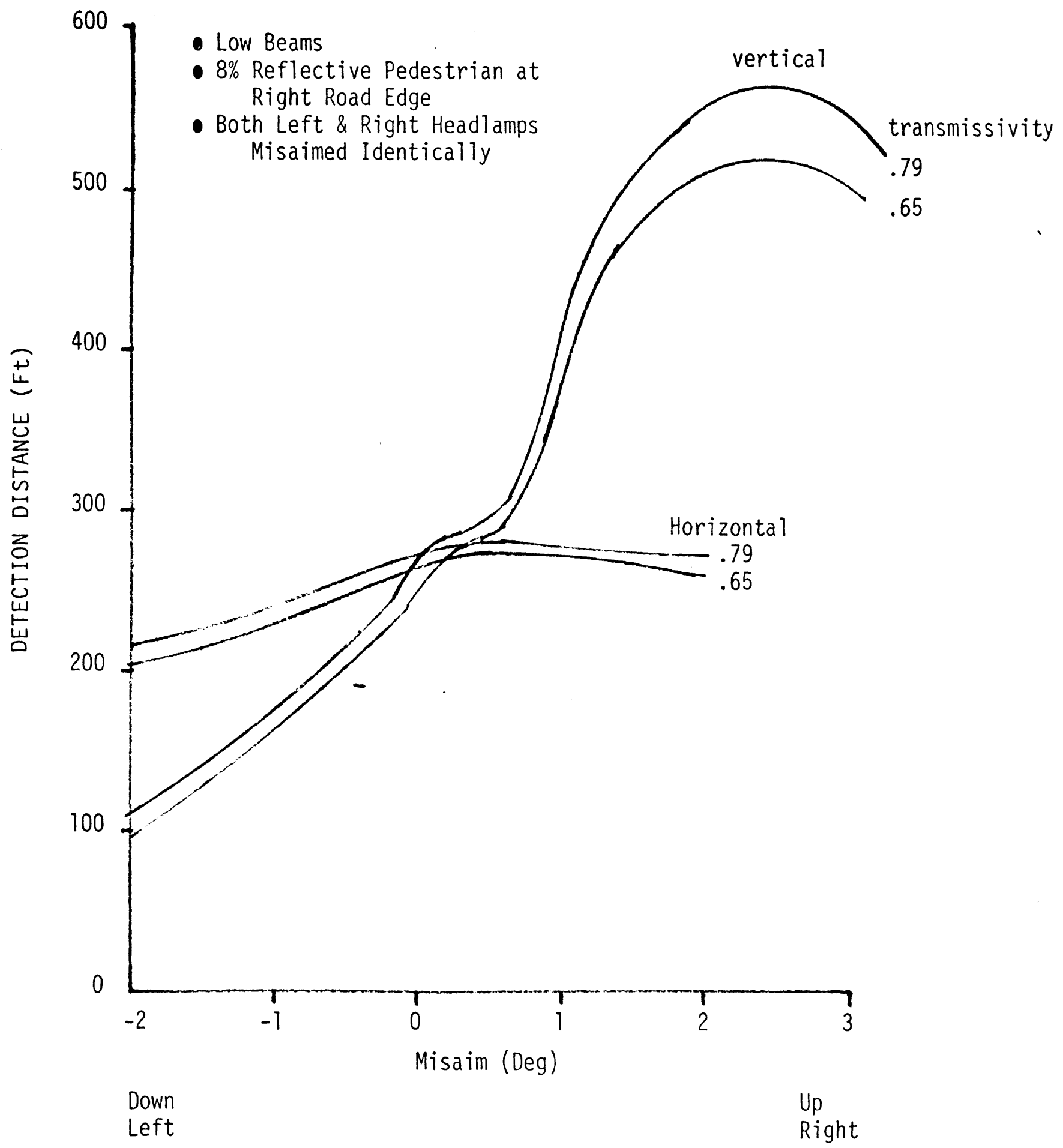

Figure 5. Detection Distance vs. Vertical and Horizontal Misaim and Windshield Transmissivity. 
quite smal1, decrements range from a minimum of $3.7 \%$ to a maximum of $9.8 \%$. The mean decrement is only $6.7 \%$.

01son and Mortimer (1973) determined from a field survey that the standard deviation of vertical headlamp aim was $.8^{\circ}$. If both headlamps are misaimed down by $.8^{\circ}$ the resulting decrement in detection distance is $32 \%$.

\section{Headl amp Dirt}

The distribution of dirt on headlamps changes drastically with weather conditions. Rumar (1975) has determined the relative proportion of cars having various levels of light reduction due to dirt accumulation in dry, wet and slushy weather. These respective distributions peaked at transmission coefficients of 85,55 and $25 \%$ for dry, wet and slushy conditions respectively.

The headlight visibility program was used to determine detection distance vs. \% light transmitted through headlamp dirt for an automobile equipped with GE 4000 low beams. Detection distance to a $15 \%$ reflective pedestrian at the right road edge was determined for clear and heat absorbing glass, figure 6 . The sensitivity of detection distance to a percent change in light transmission is not great. In this case it is a $.35 \%$ decrement in detection distance for a $1 \%$ decrement in light transmission. The sensitivity of detection distance to changes in windshield transmissivity is essentially equivalent to this. However, the change in transmissivity between clear and heat absorbing glass does not, in practice, exceed $15 \%$, whereas in the case of dirt on headlamps, a 15\% decrement in transmissivity is often the best situation found in practice and decrements of $45 \%$ in wet weather and of $75 \%$ in slushy snow conditions are quite prevalent. The decrement in visibility distance due to heat absorbing glass is approximately 16 feet. A 30\% reduction in light transmissivity when road conditions change from dry to wet produces a $40 \mathrm{ft}$. decrement in detection distance. The $60 \%$ reduction in light transmission when road conditions change from dry to slushy produce 


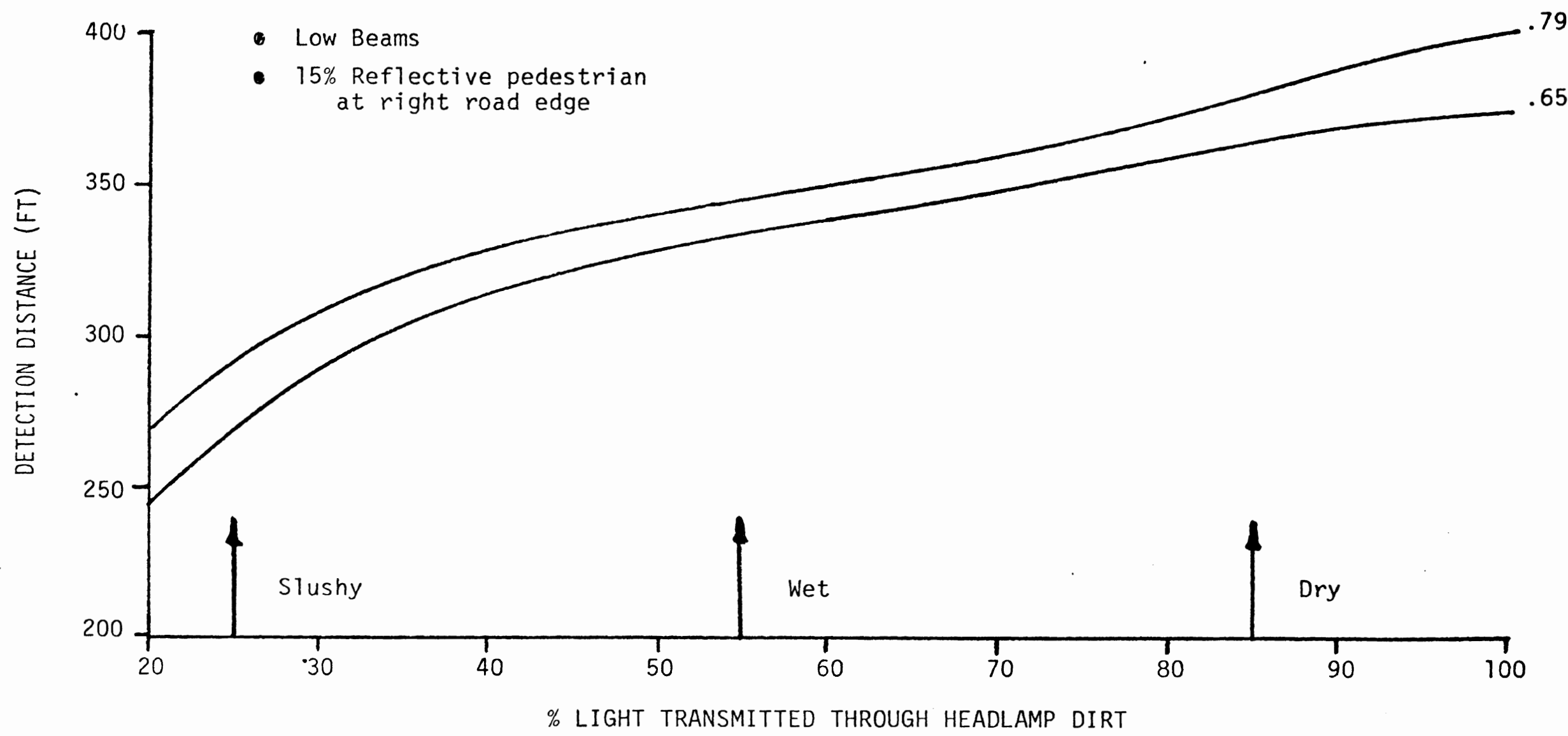

Figure 6. Detection Distance vs. \% Light Transmitted Through Headlamp Dirt and Windshield Transmissivity. 
a $95 \mathrm{ft}$. decrement in detection distance. Thus, it is clear that the headlamp dirt problem is quite significant. It is also a problem which can be easily corrected by requiring automatic headlamp washers on all new vehicles. The solution of the headlamp dirt problem would increase detection distances substantially and more then compensate for the reduction in detection distance caused by heat absorbing glass.

\section{Pedestrian Reflectance}

One factor which greatly affects visibility distance is pedestrian reflectance. Although this factor is often considered an environmental factor beyond the control of safety planners, through education and the advent of new products the reflectance of pedestrians can be improved. The marked improvement in detection distance with increases in pedestrian reflectance is readily seen in Figure 7 . Detection distance under low beam illumination to pedestrians at the right edge of the road have been determined for clear and heat absorbing glass and concrete and asphalt pavement. The dashed and solid curves represent the detection distances on concrete pavement for clear and heat absorbing glass respectively. The $x$ 's and 0 's represent the detection distance on asphalt pavement for clear and heat absorbing glass. In all cases detection distance increases with pedestrian reflectance. At lower values of reflectance, detection distance increases rapidly with pedestrian reflectance whereas at high pedestrian reflectance, detection distance increases less rapidly. Detection distance is not affected much by pavement type except at low pedestrian reflectances when the target is approximately the same reflectance as the pavement. Detection distance is usually slightly greater on asphalt pavement than concrete pavement because for pedestrian reflectances greater than $6 \%$ target-background contrast is greater for asphalt pavement. For pedestrian reflectances below $6 \%$ absolute target-background contrast may be greater for concrete pavements than asphalt pavements and detection distances 


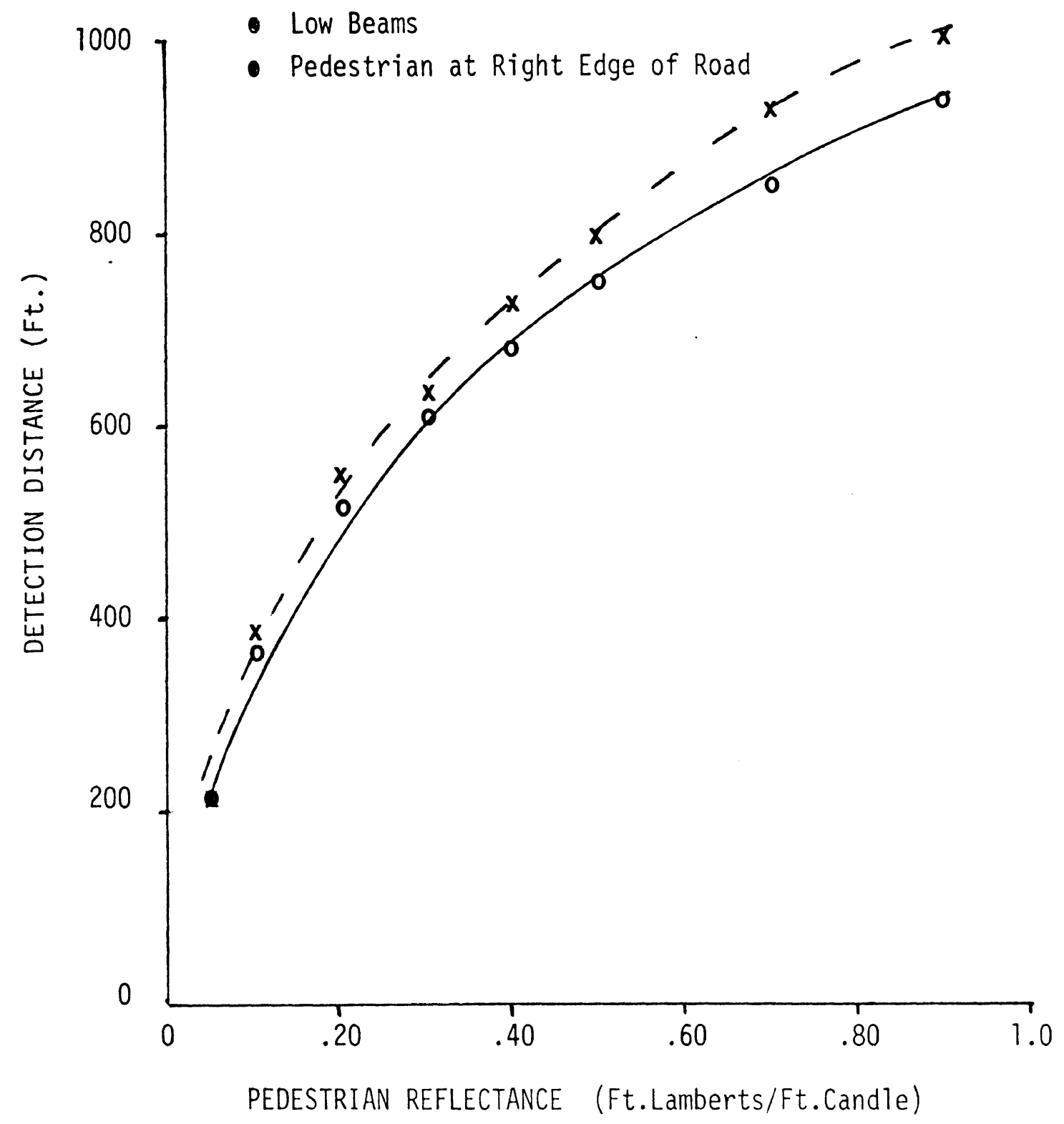

Figure 7. Detection Distance vs. Pedestrian Reflectance, Pavement Type and Windshield Transmissivity;

-..- .79 Transmissivity, Concrete Pavement;

- .65 Transmissivity, Concrete Pavement;

$x \quad .79$ Transmissivity, Asphalt Pavement;

0.65 Transmissivity, Asphalt Pavement. 
will be slightly greater on concrete pavements.

For a $10 \%$ reflective pedestrian standing against a concrete pavement, the decrement in detection distance due to heat absorbing glass is $6.7 \%$ (360 ft. for clear vs. $336 \mathrm{ft}$. for heat absorbing). For a $90 \%$ reflective pedestrian standing against a concrete pavement the detection distance decrement due to heat absorbing glass is $6 \%$ (998 ft. vs. $938 \mathrm{ft}$. )

\section{Low Beam Glare}

The effects of low beam glare on the detection distance to an $8 \%$ reflective pedestrian stationed at the right edge, center and left edge of the lane have been determined. The results are shown in Figure 8 as curves of low beam detection distance vs. glare car distance, lateral position and clear vs. heat absorbing glass.

Detection distance is greatest for pedestrians at the right edge of the road and decreases monotonically for pedestrians stationed at the center and left edge of the road. Thus, for a clear windshield without glare, detection-distance is $300 \mathrm{ft}$. to a pedestrian at the right road edge, $260 \mathrm{ft}$. to a pedestrian in the center of the road and $200 \mathrm{ft}$. to a pedestrian at the left lane edge. For pedestrians at the right and center of the lane, low beam glare does not affect detection distance significantly.

For a pedestrian at the left edge of the lane, detection distance varies from a maximum of $200 \mathrm{ft}$. Without glare to a minimum of $127 \mathrm{ft}$. When the glare car is $200 \mathrm{ft}$. away. The decrement in detection distance due to heat absorbing glass is only $3.5 \%$ for a pedestrian at the right edge, $4.0 \%$ for pedestrians in the road center and varies from $11.3 \%$ to $7.4 \%$ for a pedestrian at the left edge of the lane. The maximum decrement when there is no glare is 11.3:, when the glare car is $600 \mathrm{ft}$. away the decrement is $7.4 \%$.

The reasons for the larger detection distance decrements at the left edge was revealed in the detailed program printout. For 


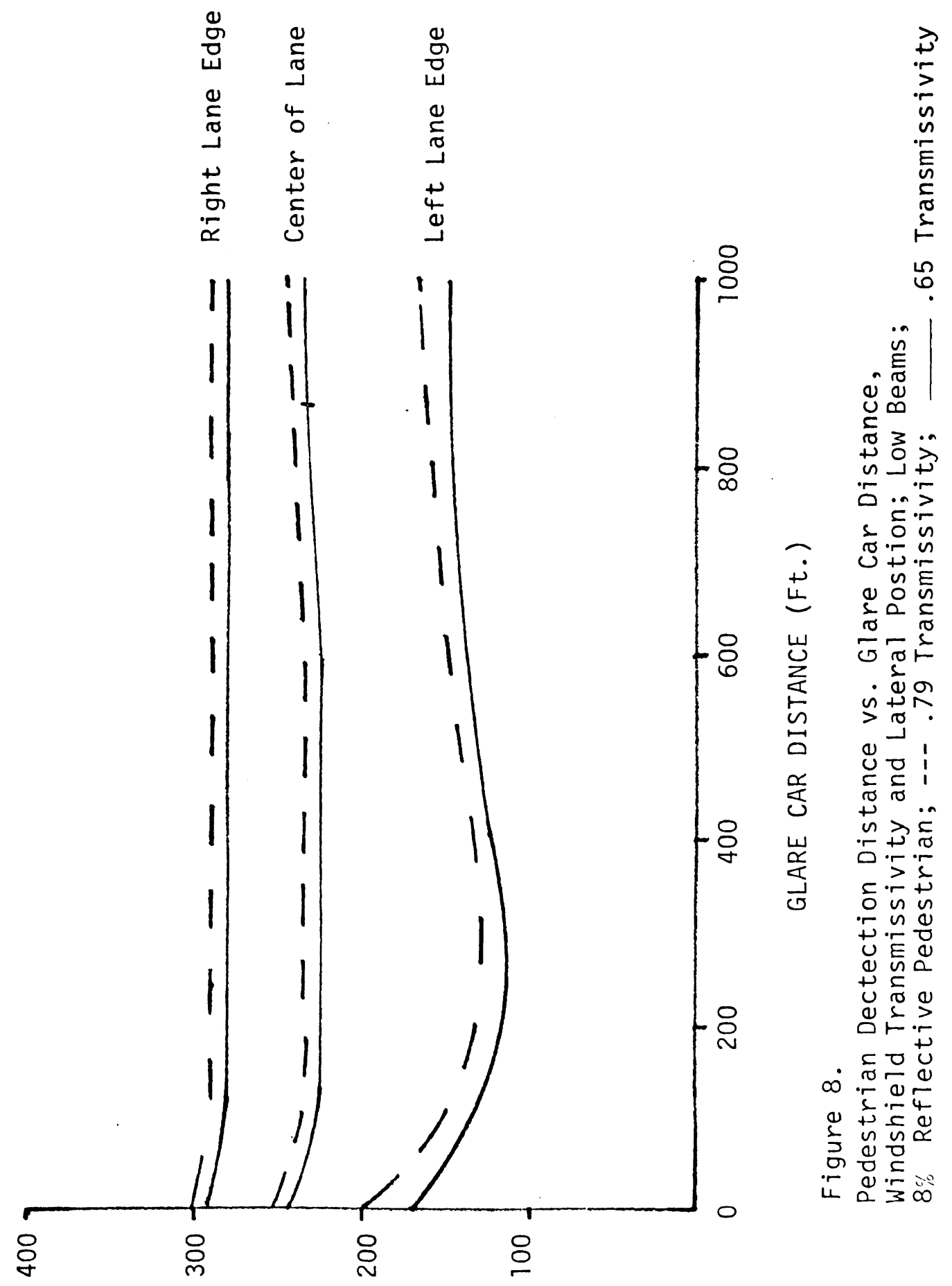

$(\cdot 7\lrcorner) \exists J N \forall L S I O$ NOI $\perp J \exists \perp \exists O$ 
the pedestrians at the left lane edge, the most intense part of the beam pattern falls on the feet of the pedestrian, with intensity decreasing rapidly with increasing height along the pedestrians contour. Thus, this situation is accurately described by the ISO-C models of Blackwell and Haber. However, this situation is quite infrequent and usually the ISO-B model with its lower reduction in visibility distance is closer to the truth.

\section{High Beam Glare}

Detection distance to an $8 \%$ reflective pedestrian stationed in the road center has been determined for a subject vehicle equipped with GE 6014 high beams facing a glare vehicle equipped with high beams, Figure 9. In the absence of a glare vehicle the high beam lamps produce large detection distances $(671 \mathrm{ft}$. for a clear windshield). However, in the presence of a glare vehicle equipped with high beams, the veiling brightness is so great as to reduce detection distance to $72 \mathrm{ft}$. When the glare vehicle is $200 \mathrm{ft}$. away. At greater glare car distances the veiling brightness is less intense and detection distance approaches the detection distance in the absence of glare.

Compared to the variation in detection distance with glare car distance the decrement in detection distance due to heat absorbing glass is small. For the $8 \%$ reflective pedestrian stationed in the center of the road the decrement is largest, 13\%, when there is no glare vehicle present. Evidently, this situation corresponds to Haber's ISO-C model. However, the detection distance provided by high beams is so great under these circumstances that even with a $13 \%$ reduction, the detection distance is quite good. In the presence of a glare vehicle, the average reduction in detection distance is only $5.5 \%$. At a glare car distance of 300 feet, evidently there is no decrement in detection distance. 




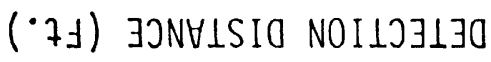




\section{Road Topography - Horizonal Curvature}

An important environmental factor affecting visibility distance is road topography. Although the safety planner has no control over existing roadways it may be possible to develop headlamp beam patterns which are optimized to produce maximum visibility for prevailing topographical conditions.

The effect of horizontal road curvature on low beam detection distance to $8 \%$ reflective pedestrians is shown in Figure 10 . Under low beam illumination, horizontal road curvature produces variations in detection distance of 200 feet for pedestrians stationed in the road center when road curvature varies from $3 \mathrm{deg} / 100 \mathrm{ft}$. left to 3 $\mathrm{deg} / 100 \mathrm{ft}$. right. For pedestrians stationed at the right edge of the road, horizontal curvature produces a maximum variation in detection distance of $125 \mathrm{ft}$. Because the low beam pattern favors the right side of the road, under most conditions of horizontal curvature detection distance is greater to pedestrians at the right road edge. However, as curvature increases to the right the detection distance gap to pedestrians on the right and in the center diminishes until finally there is a crossover corresponding to the transition through the hot spots of the headlamp beam patterns.

Variations in detection distance due to heat absorbing glass for various degrees of road curvature vary from $2.2 \%$ to $11 \%$; the mean variation is approximately $6 \%$. Thus, the effect of heat absorbing glass on detection distance is small compared to the effect of horizontal curvature.

\section{Vertical Curvature}

A parametric analysis was performed to determine the effect of changes in grade on detection distance. Positive changes in grade correspond to increases in road slope (producing a valley between tangent sections), while negative changes in grade correspond to 




(7t) $\exists$ JNHISIO NOIIJ3130 
decreases in road slope (producing a hill between tangent sections). In all cases the rate of change of curvature has been held fixed and the desired change in grade is attained by controlling the length of the curve between tangent sections. (A Policy of Geometric Design of Rural Highways (1965) places limits on the maximum degree of vertical curvature as a function of design speed. At a design speed of $55 \mathrm{mph}$ the maximum permissible rate of change in vertical curvature is $.76 \% 100$ feet.) The low beam detection distance to $8 \%$ reflective pedestrians stationed at the right road edge has been determined for changes in grade varying from $-8 \%$ to $+8 \%$, Figure 11. Through a clear windshield detection distance varies from a maximum of $579 \mathrm{ft}$. for a change of grade of $-4 \%$ to a minimum of $229 \mathrm{ft}$. at a change of $+4 \%$. Thus, changes in grade can produce $350 \mathrm{ft}$. variations in detection distance. The high sensitivity of detection distance to changes in grade resembles the detection distance sensitivity to vertical misaim. Both these situations alter the vertical location of the pedestrian in the headlamp beam. Positive changes in grade cause the pedestrian to move up in the beam (just as misaiming down causes the pedestrian to move up in the beam pattern) causing a decrease in candle power reaching the pedestrian and reducing detection distance. Negative changes in grade cause the target to move down in the beam, increasing candle power and detection distance.

In comparison to change in grade, heat absorbing glass has a minimal affect on detection distance. The decrement due to heat absorbing glass for various changes in grade varies from a low of $3.2 \%$ to a high of $6.9 \%$; the mean variation is approximately $5 \%$.

Wet Pavements

The driver's ability to see targets under adverse weather conditions has long been a concern of safety researchers. Visibility of targets under wet road conditions is of particular interest. 


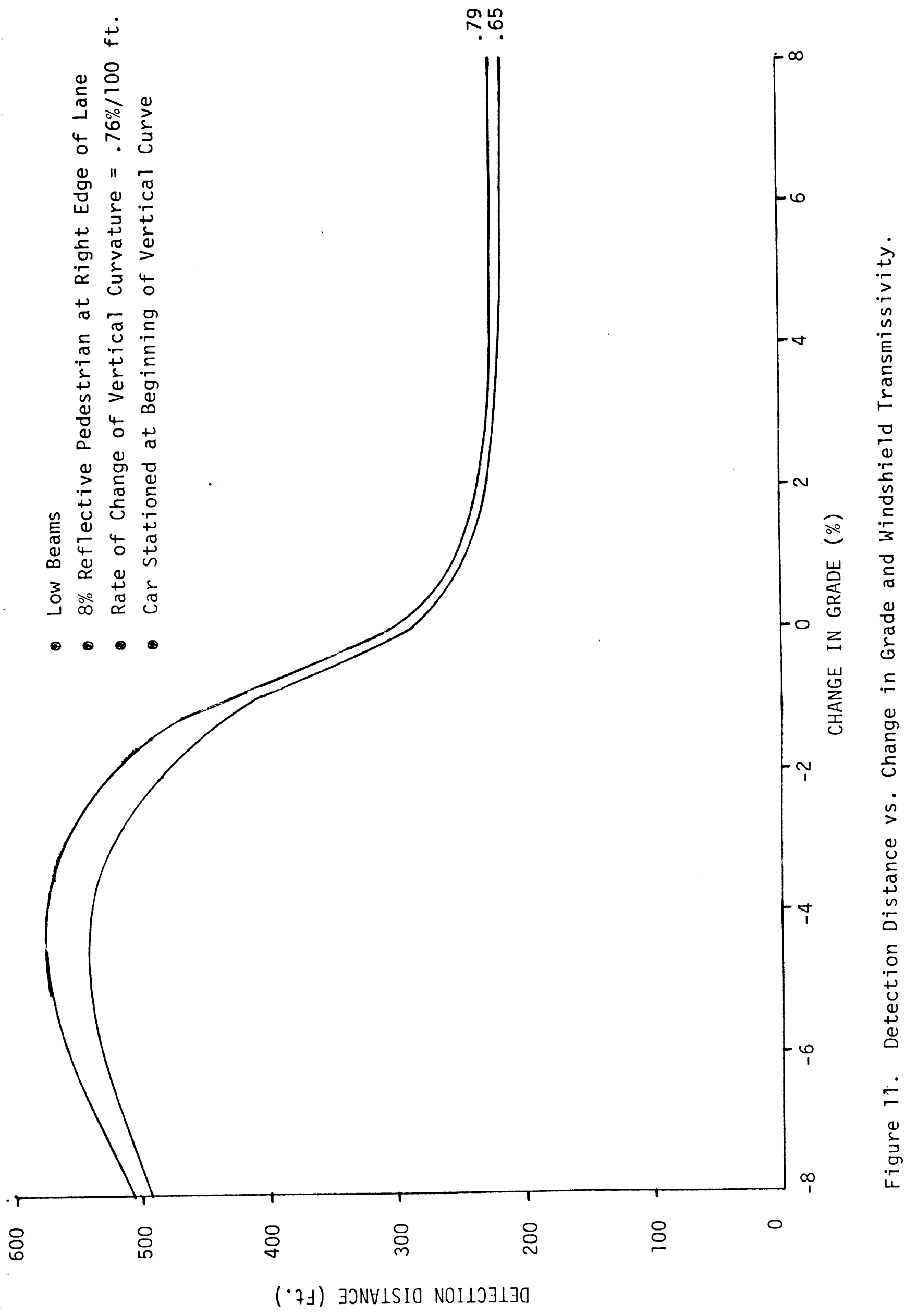


The situation being modelled is a pedestrian standing on a wet, straight, flat pavement at the end of a rain storm. Under these conditions the reflective properties of the pavement are very similar to those of a mirror. That is the wet pavement exhibits strong specular reflection, (high reflectance when the angle of incidence is equal to the angle of reflection), but very low retro-reflectivity.

Most drivers are aware of the disappearance of lane markings and of the road itself during rain storms. This is because both the lane markers and the pavement itself reflect less light back to the driver's eye reducing contrast. However, in the absence of glare, pedestrians are actually more visible on wet pavements that they are on dry pavements. This is due to the fact that the pedestrian reflectance does not decrease and thus his luminance does not decrease in the rain, while the darkening of the wet pavement increases contrast causing the pedestrian to be more visible.

In the presence of an oncoming glare car the wet pavement acts to increase the disability glare by specularly reflecting the light from the oncoming glare lamps into the subject driver's eye. Thus, both the direct and reflected glare from the oncoming car contributes to the veiling brightness. On a wet, straight, flat pavement the specular glare can be modelled by substituting a virtual pair of headlamps for the specular reflection from the actual glare lamps. These virtual lamps are located below the actual lamps at a distance below the pavement equal to the height of the lamps above the pavement, Figure 13. The vertical axis of the virtual headlamps is inverted relative to the actual headlamps (mirror image). Thus the program in computing detection distance to pedestrians on wet pavement in the presence of a glare car, computes the veiling brightness due to the actual and image headlamps.

The detection distances on wet pavement for low beams facing low beams is shown as a function of glare car distance in Figure 12. 


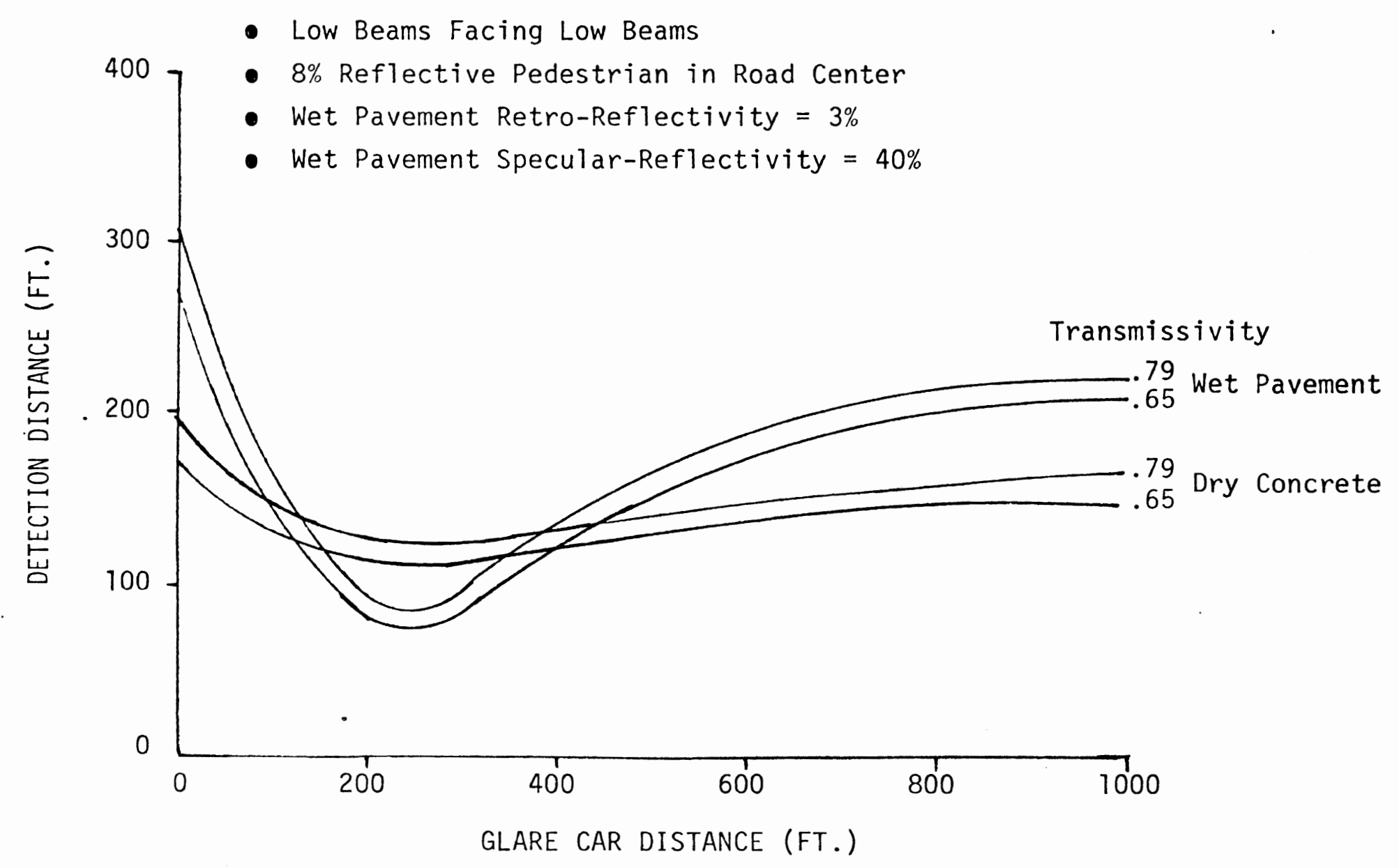

Figure 12. Comparison of Target Detection Distance on Wet and Dry Pavement, for Clear and Heat Absorbing Glass 


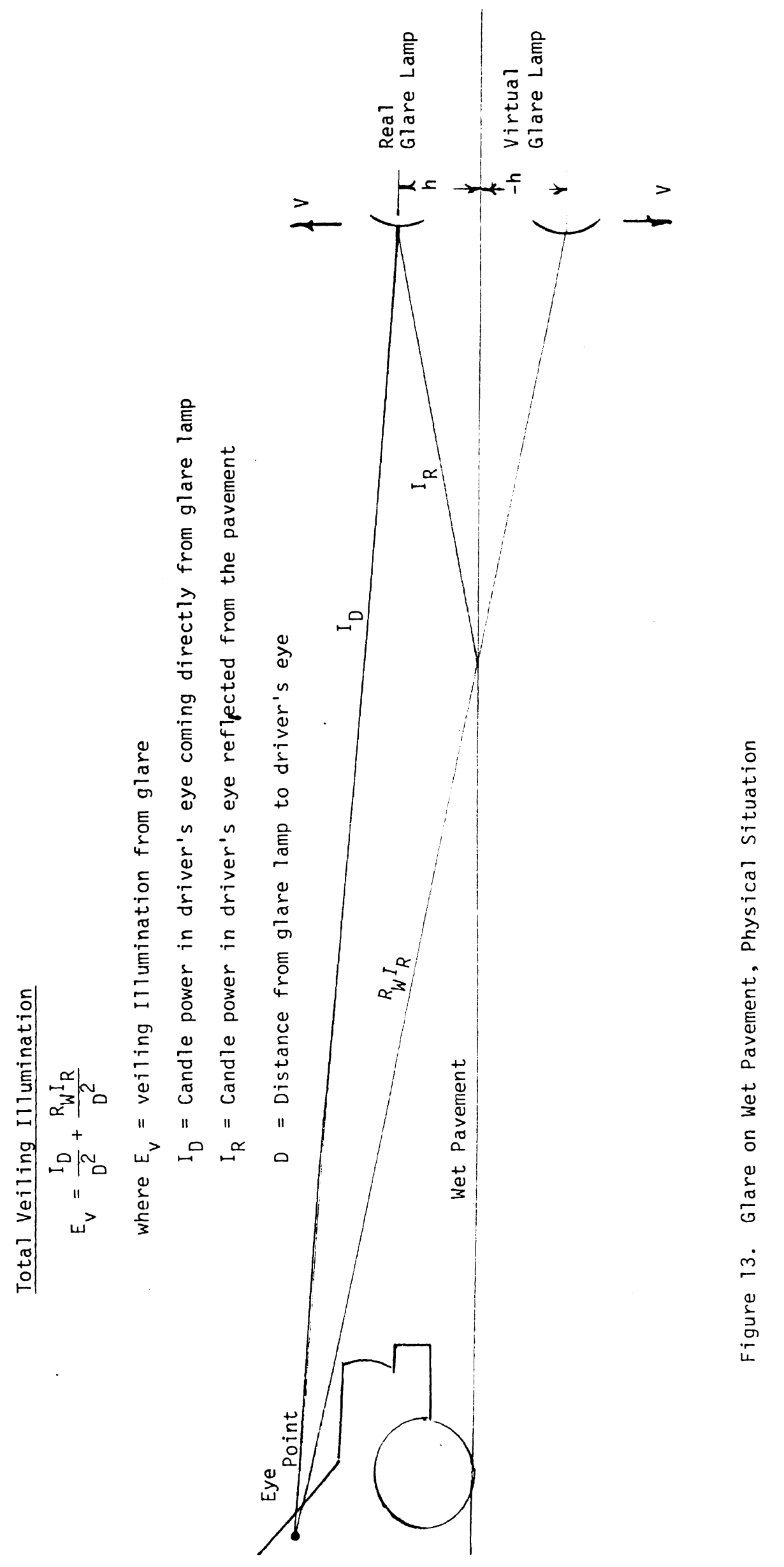


The pedestrian is $8 \%$ reflective and standing in the center of the road. Both subject and glare vehicles have identical low beams. In the absence of glare the pedestrian detection distance is greater on the wet pavement than the dry. Through a clear windshield the pedestrian detection distance on wet pavement is $310 \mathrm{ft}$., while on dry pavement it is only $200 \mathrm{ft}$. The presence of a glare car produces large decrements in the detection distance on wet pavement, while on dry concrete glare detection distance is affected less drastically.

On wet pavement detection distance varies from a maximum of 310 feet to a minimum of 91 feet.

The reduction in detection distance due to heat absorbing glass is much less than the reduction caused by glare on the wet pavement. The decrement in detection distance due to heat absorbing glass varies from $0 \%$ when the glare car is 300 feet away from the subject car to $12 \%$ when there is no glare car present. The mean reduction in detection distance is approximately $7.8 \%$.

Visibility of Delineation

The driver's ability to see roadway delineation lines is an important factor affecting his lane maintenance ability.

Again detection distance may be used as a measure of visual performance. The HVP has been used to compute the detection distance to a $15^{\prime} \times 4^{\prime \prime}$ white reflectorized delineation tape of specific luminance .18 candelas/ft.-candle/ft. ${ }^{2}$ (minimum federal specification).

Because a delineation line is a horizontal target, the projected image in the driver's field of view is greatly forshortened. The HVP performs the computations which project the delineation line into the viewing plane and computes the equivalent area for this projected target. Detection distance for clear and heat absorbing 
glass were determined for a $15 \mathrm{ft}$. delineation line located in the center of a $24 \mathrm{ft}$. wide, straight, flat roadway. Detection distance through the .79 transmissivity clear windshield is 315 feet while detection distance through the .65 transmissivity heat absorbing windshield was 300 feet; the decrement due to heat absorbing glass is only $4.8 \%$. This decrement should not adversely affect driver's lane maintenance ability.

Conclusions

There are many other vehicle and environmental factors affecting visibility distance besides the nature of the windshield glass. Under normal nighttime driving conditions the variation in pedestrian detection distance that is due to these other factors is often significantly greater than the variation in detection distance due to the type of windshield glass.

The following is a summary of our research findings on the effects of various vehicles and environmental factors on pedestrian detection distance.

1. The decrement in visibility distance to a pedestrian due to the use of heat absorbing glass rather than clear glass varies from a low of $0 \%$ under certain glare conditions to a high of $12 \%$ when the pedestrian has a low reflectance and the most intense headlamp illumination is directed at the pedestrian's feet and there is no glare. Under most circumstances the decrement in visibility distance due to heat absorbing glass is only $6 \%$.

2. Headlamp dirt is a serious factor adversely affecting detection distance. Decrements in light transmission of 15,45 , and $75 \%$ are quite prevalent under dry, wet, and slushy road conditions respectively. Whereas the decrement in detection distance to a $15 \%$ reflective pedestrian 
due to heat absorbing glass is 16 feet the expected decrement in detection distance when road conditions change from dry to wet (a 30\% reduction in light transmission) is 40 feet. The use of headlamp washers would increase detection distance enough to more than compensate for the reduction in detection distance caused by heat absorbing glass.

3. Headlamp misaim is another vehicle factor seriously affecting detection distance. If both low beam headlamps are misaimed down $.8^{\circ}$ corresponding to a $1 \sigma$ variation in the aim of each headlamp, detection distance will diminish by $32 \%$.

4. Heat absorbing glass reduces visibility distance to a white reflectorized delineation line by only $4.8 \%$. This reduction should not adversely affect the driver's guidance and lane maintenance ability. 


\section{REFERENCES}

Bernstein, A. A Physiological Math Model for Human Visual Target Detection. Paper presented to the Vision Lunch, Mental Health Research Institute, University of Michigan. Jan. 8, 1976. Recorded with the library of the Highway Safety Research Institute.

Bernstein, A. Prediction of Target Detection Thresholds on the Basis of Physiological Considerations. Proceedings of the Human Factors Society. Oct. 1974.

Bernstein, A. Measurement of Pavement Brightness Factor. Memorandum, Environmental and Safety Engineering, Ford Motor Co. July, 1974.

Bhise, V.D., McMahan, P.B., and Farber E.I. Predicting Target Detection Distance with Headlights, Presentation to the Transportation Research Board. January, 1976.

Blackwell, H.R. Brightness Discrimination Data for the Specification of the Quantity of Illumination. Illum. Engineering, Vo1. XLVII, No. 11, November, 1952.

Blackwell, H.R. and McCready, D.W. Foveal Contrast Thresholds for Various Durations of Single Pulses, Engineering Research Institute, The University of Michigan, 1958.

Blackwell, H.R. Visual Detection at Low Luminance Through Optical Filters. Highway Research Board Bulletin, No. 89, pp. 43-61, 1954.

DeGroot, S.G., and Gebhard, J.W. Pupil Size as Determined by Adapting Luminance. J. Opt. Soc. Am., 42, 492, 1952.

Dunipace, D.W., Strong, J., and Huizinga, M. Prediction of Nighttime Driving Visibility from Laboratory Data, Applied Optics, 13, 2732-2733, November 1974.

Haber, H. Safety Hazard of Tinted Automobile Windshields at Night. J. Opt. Soc. Am., 45, 413, 1955.

Heath, W. and Finch, D.M. Effect of Tinted Windshields on NighttimeVisibility Distances. Highway Research Board, Bulletin 68, January 1953.

01son, P.L. and Mortimer, R.G. Investigation of Some Factors Affecting the Aim of Headlamps, University of Michigan. UM-HSRI-HF-73-13, January 1973. 
Roper, V.J. Nighttime Seeing Through Heat-Absorbing Windshields, Highway Research Board Bulletin 68, January 1953.

Rumar, K. Dirty Headlights-Frequency and Visibility Effects, Department of Psychology, University of Upsula, Sweden. Report 36, 1973. 